\section{POS0962 PATIENT-REPORTED IMPACT OF AXIAL SPONDYLOARTHRITIS ON WORKING LIFE. RESULTS FROM THE SPANISH ATLAS}

M. Garrido-Cumbrera ${ }^{1}$, E. Collantes-Estévez ${ }^{2}$, V. Navarro-Compán ${ }^{3}$, P. Zarco Montejo ${ }^{4}$, C. Sastré 5 , S. Sanz-Gómez ${ }^{1}$, J. Correa-Fernández ${ }^{1}$, J. GratacosMasmitja ${ }^{6}$ on behalf of Atlas working group. ${ }^{1}$ Universidad de Sevilla, Health \& Territory Research (HTR), Seville, Spain; ${ }^{2}$ Reina Sofia University Hospital, Rheumatology Department, Cordova, Spain; ${ }^{3}$ Hospital Universitario La Paz, IdiPaz, Madrid, Spain; ${ }^{4}$ Hospital Universitario Fundación Alcorcón, Rheumatology Department, Madrid, Spain; ${ }^{5}$ Novartis Farmacéutica Spain, Immunology, Hepatology and Dermatology, Barcelona, Spain; ${ }^{6} \mathrm{Hospital}$ Universitaria Parc Tauli, Rheumatology Department, Sabadell, Spain

Background: Axial spondyloarthritis (axSpA) impacts negatively on multiple dimensions of patient's life, including their working life.

Objectives: The present study aims to evaluate burden of disease ox axSpA patients by working status, work-related issues and their associations and determinants in a Spanish sample.

Methods: The Atlas 2017 is an extensive cross-sectional patient survey conducted in Spain (2016), validated by a multidisciplinary group of experts on spondyloarthritis. Participants were recruited through an on-line panel and patient organizations. Participants were classified as active (employed, unemployed between 15-64 years) and inactive (retirees, on sick leave, students and homemakers). Those employed were asked to report work-related issues (WRIs) due to axSpA (sick-leave, difficulty fulfilling work hours, missing work for doctors' appointments, reducing working hours or taking days off) in the past 12 months. Diagnostic delay, disease activity (BASDAI), spinal stiffness (3-12), functional limitation (0-54) and psychological distress (General Health Questionnaire, GHQ-12 [0-12]) were compared between employed patients with or without WRIs using a Mann-Whitney and Kruskal-Wallis test.

Results: Data from 680 patients were collected: mean age was $47 \pm 11$ years, $52.5 \%$ were female and $36.9 \%$ were university educated. Mean disease duration and diagnostic delay were $20.9 \pm 12.2$ and $8.5 \pm 7.7$ years, respectively, and mean BASDAl was $5.5 \pm 2.2$. A total of $63.6 \%(n=415)$ were considered active population, of which $49.8 \%$ ( $n=325)$ were employed. Of those employed, $54.3 \%$ reported a WRI, specifically $37.1 \%$ took sick leave, $44.1 \%$ had difficulties in fulfilling the working hours, $42.9 \%$ missed work due to doctor's appointments $37.1 \%$ took sick leave, $18.2 \%$ reported that their professional life had suffered, $12.3 \%$ asked for some days off, $12.3 \%$ changed shift sometimes and $7.6 \%$ had to give up their previous job. Among all patients, 95.5\% faced (or believed they would) difficulties finding a job due to axSpA. Experiencing WRIs due to axSpA was significantly associated in the univariable analysis with higher disease activity, self-reported spinal stiffness, longer diagnostic delay, higher functional limitation and higher level of psychological distress $(p<0.001)$. However, the highest levels of disease burden were reported by unemployed participants (see Table 1).

Table 1. Differences between employees with/without work-related issues and between employed/unemployed participants in relation to sociodemographic and patient-reported outcomes

\begin{tabular}{|c|c|c|c|c|}
\hline \multirow{2}{*}{$\begin{array}{l}\text { Reference group } \\
\text { Subgroup }\end{array}$} & \multicolumn{2}{|c|}{ Employed } & \multicolumn{2}{|c|}{ Active Population } \\
\hline & Any WRI & With no WRIs & Employed & Unemployed \\
\hline N size & n: 170 & n: 143 & $\mathrm{n}: 325$ & n: 90 \\
\hline \multicolumn{5}{|c|}{ Sociodemographic characteristics } \\
\hline Age (years) & $41.9 \pm 7.9$ & $44.2 \pm 9.4$ & $42.9 \pm 8.6^{*}$ & $42.0 \pm 9.1^{*}$ \\
\hline Gender (Male) & 79 (46.5) & $75(52.4)$ & $159(48.9)$ & $36(40.0)$ \\
\hline Education level (University) & $80(47.1)^{\star}$ & $68(47.6)^{*}$ & $153(47.1)$ & $21(23.3)$ \\
\hline Marital status (Married) & $110(64.7)$ & $109(76.2)$ & $231(71.1)$ & $54(60.0)$ \\
\hline \multicolumn{5}{|l|}{ Patient-reported outcomes } \\
\hline BASDAI $(0-10)$ & $5.7 \pm 1.8^{\star *}$ & $4.5 \pm 1.9^{\star \star *}$ & $5.2 \pm 1.9^{\star *}$ & $6.3 \pm 1.9^{* *}$ \\
\hline Spinal Stiffness (3-12) & $6.7 \pm 2.7^{\star \star}$ & $6.1 \pm 2.4^{\star \star}$ & $6.5 \pm 2.6^{\star \star}$ & $7.8 \pm 2.3^{\star \star}$ \\
\hline Functional Limitation (0-54) & $43.9 \pm 8.8^{\star \star}$ & $36.9 \pm 10.3^{\star \star}$ & $40.6 \pm 10.1^{\star \star}$ & $45.0 \pm 8.4^{\star \star}$ \\
\hline GHQ-12 (0-12) & $6.6 \pm 4.2^{\star \star}$ & $3.0 \pm 3.5^{\star \star}$ & $4.9 \pm 4.3^{\star \star}$ & $7.6 \pm 4.2^{\star \star}$ \\
\hline Anxiety & $35(20.6)^{\star}$ & $16(11.2)^{\star}$ & $52(16.0)^{\star}$ & $25(27.8)^{\star}$ \\
\hline Depression & $29(17.1)^{\star}$ & $4(2.8)^{*}$ & $33(10.2)^{\star \star}$ & $21(23.3)^{\star \star}$ \\
\hline
\end{tabular}

Note: WRI: Work-related issue ${ }^{\star \star} p$-value $<0.001$; ${ }^{*} p$-value $<0.05$

Conclusion: Results reveal a relevant impact of axSpA in patient working life. Approximately two out of three patients employed experienced WRIs due to axSpA, being associated to worse disease outcomes and poorer psychological health. However, those who were unemployed faced a harsher situation reporting even poorer disease-related and psychological health outcomes. As psychological health appears impaired severely in axSpA patients regardless of their employment status it should be key for a holistic approach to patient care. Acknowledgements: This study was supported by Novartis Spain. The authors would like to thanks all patients who participated in the Atlas study.
Disclosure of Interests: Marco Garrido-Cumbrera: None declared, Eduardo Collantes-Estévez Grant/research support from: Abbvie, BMS, Lilly, MSD, Novartis, Pfizer, Roche, and UCB, Victoria Navarro-Compán Grant/research support from: Abbvie, BMS, Lilly, MSD, Novartis, Pfizer, Roche, and UCB., Pedro Zarco Montejo: None declared, Carlos Sastré Employee of: Novartis Farmacéutica Spain, Sergio Sanz-Gómez: None declared, José Correa-Fernández: None declared, Jordi Gratacos-Masmitja Grant/research support from: Abbvie, BMS Lilly, MSD, Novartis, Pfizer, Roche, and UCB.

DOI: 10.1136/annrheumdis-2021-eular.985

\begin{tabular}{|l|l}
\hline POS0963 & POWER AND SPECTRAL DOPPLER ULTRASOUND AS \\
& A SCREENING TOOL IN THE DIAGNOSTIC COURSE \\
& OF SUSPECTED AXIAL SPONDYLOARTHITIS: \\
& PRELIMINARY DATA FROM A LARGE MONOCENTRIC \\
COHORT
\end{tabular}

P. Falsetti ${ }^{1}$, E. Conticini ${ }^{1}$, C. Baldi' ${ }^{1}$, M. Bardelli ${ }^{1}$, R. D'alessandro ${ }^{1}$, S. G. Al Khayyat $^{1}$, M. A. Mazzei ${ }^{2}$, L. Cantarini ${ }^{1}$, B. Frediani ${ }^{1} .{ }^{1}$ University of Siena, Rheumatology Unit, Siena, Italy; ${ }^{2}$ University of Siena, Diagnostic Imaging Unit, Siena, Italy

Background: Sacroiliac joints (SIJs) involvement is a characteristic feature of Spondylarthritis (SpA). Magnetic resonance imaging (MRI) has been included in the new Assessment of SpA International Society (ASAS) criteria for the classification of non-radiographic axial SpA. Power Doppler ultrasound (PDUS) and spectral Doppler US have been used in few works, also from our group, to evaluate the inflammatory activity of the SIJs, in comparison with MRI, with different results.

Objectives: We aimed to evaluate the value of PDUS with spectral wave analysis (SWA) in the assessment of suspected active sacroilitis (SI). PDUS of SIJs was used as a screening tool alongside the routine PDUS assessment of peripheral joints.

Methods: 143 patients (114 females and 29 males, mean age 46,2 years, mean BMI 25.9) with new onset of inflammatory back pain (IBP), were included. Peripheral symptoms were allowed. Every patient underwent a PDUS examination of SIJs as previously reported. The sonographer was blinded to the clinical data. An Esaote Twice US machine, with convex 1-8 MHz and linear 6-18 MHz probes, was used, with standardized parameters. PD signals detected in the SIJs, were scored with a 3 -points scale: $0=$ absence of signals, $1=$ isolate vessels, $2=$ more than one vessel. The signals were also classified as intra-articular (vascularity from deep joint and inter-osseous ligament) or peri-articular (vascularity along posterior sacroiliac ligament). SWA was applied to the same vessels calculating the Resistive Index (RI) (Figure 1). A PDUS diagnosis of active SI was made with a grade 1 of vascularity and $R \mid<0,60$, or grade 2 of vascularity and $R \mid<0,70$. PDUS multi-site examination of peripheral joints and entheses was also performed; entheseal involvement was scored with Belgrade Ultrasound Enthesitis Score (BUSES) and as global enthesitic charge (GEC). Every patient underwent MRI of SIJs within 2 weeks, and before to start pharmacologic treatment. The non-parametric Spearman rank test and univariate linear regression analysis was applied using InStat GraphPad statistical package.

Results: A time of 5-8 minutes was sufficient to set and to complete PDUS/SWA examination on both SJJs. All patients considered this examination quick, not painful and substantially comfortable. PD signals were detected in 124 patients (mean RI 0,56). Bone marrow edema (BME) lesions (active SI on MRI) were detected in 94 patients. A final diagnosis of SpA was made in 103 patients (81 females, 22 males). Among SpA patients 24 had psoriasis, 3 inflammatory bowel disease, 3 uveitis, 5 were B27+, and they had mean BUSES of 4,1 and GEC of 1,2. The mean SIJs PDUS score was 1,3 in SpA and 0,52 in not-SpA patients The mean SIJs RI was 0,53 in SpA and 0,68 in not-SpA patients. A significant correlation was demonstrated between MRI and PDUS diagnosis of $\mathrm{SI}(\mathrm{r}=0,6486$, $p<0,0001)$, between MRI diagnosis and PD grading $(r=0,4937, p<0,0001)$. The split analysis of peculiar parameters of imaging between the two methods also showed significant correlation: periarticular vascularity showed correlation with post-contrast MRI evidence of posterior capsulitis and enthesitis $(p=0,001)$, as SIJs BME correlated with intra-articular PD signals $(p<0,001)$. RI from SWA analysis was inversely correlated with MRI diagnosis of active $S I(p<0.0001)$. SIJs PD demonstrated a significant correlation with SIJs pain $(p<0,001)$, but not with inflammatory reactants, GEC, peripheral synovitis, and a weak correlation with BUSES $(p=0,038)$.

Conclusion: SIJs PDUS/SWA may be an optional method for preliminary screening of active $\mathrm{SI}$, as a feasible, cheap and an accurate diagnostic tool, compared with MRI as a gold standard for nr-Axial SpA. PD US in SI. Right S joint with a PD signal within inter-osseous ligament (curved arrow), where spectral PD analysis shows a RI of 0,62. Normal vessels (with high RI, unshowed) can be observed into the first sacral foramen (arrowhead). The first sacral apophysis (arrow) protrudes from the sacrum profile. 